\title{
LII. The positive column in oxygen
}

\section{Rev. P.J. Kirkby}

To cite this article: Rev. P.J. Kirkby (1908) LII. The positive column in oxygen, Philosophical Magazine Series 6, 15:88, 559-569, DOI: 10.1080/14786440809463797

To link to this article: http://dx.doi.org/10.1080/14786440809463797

$$
\text { 册 Published online: } 16 \text { Apr } 2009 .
$$

Submit your article to this journal

LII Article views: 2

Q View related articles $\asymp$ 


\section{[ 559 ]}

LII. The Positive Column in Oxygen.

By the Rev. P. J. Kirkby, Fellow of New College, Oxford*.

QOME researches in which I have recently been engaged led me to investigate the electric force in the "positive column" when a steady electric discharge passes through oxygen at low pressures between two plane parallel electrodes placed in a straight glass tube.

The "positive column" in such a cylindrical discharge may, in view of common experience, be defined as a region of the discharge terminating at or close to the anode or positive electrode where the electric force-i.e. the potential difference per centimetre-is constant or nearly constant. Close to the cathode there is an abrupt fall of potential called the "cathode fall." Here there is a bright glow lining the cathode which is unmistakable. Between this glow and the positive column there is nothing to catch the eye at pressures of a few millimetres of mercury. The positive column is easily recognized as a long faintly luminous column of a colour which varies with the gas through which the discharge passes, being in oxygen either pale violet or a curious green.

At pressures of the order $1 \mathrm{~mm}$. it begins at a distance of about $6 \mathrm{cms}$. from the cathode and extends right up to the anode. The nearest point of the positive column to the cathode may be called the foot of the positive column. The electric foree is remarkably constant throughout this region: it depends chiefly on the pressure, but is said to vary $\dagger$ to some extent with the diameter of the discharge-tube.

The results of my experiments show that in oxygen the variation of the electric force in the positive column with the pressure presents exceptional features which do not appear to have been noticed." In the first place, the force is very much smailer than in the other common gases; secondly, instead of diminishing continually with the pressure it reaches a minimum at about $2.0 \mathrm{mms}$. pressure; and thirdly, there is a sharp discontinuity in its value at a pressure of $\cdot 8 \mathrm{~mm}$. as measured by the McLeod gauge.

The methods hitherto employed to investigate the electric force in the positive column have generally involved the use of exploring wires fused into the sides of the tubes : their difference of potential during a discharge divided by their distance apart was assumed to give the electric force in the undisturbed gas. This method is open' to the criticism that

* Communicated by the Author.

† J. J. Thomson, 'Conduction of Electricity through Gases,' ch. xv. 
the introduction of the wires in the sides must disturb the uniformity of the surface of the discharge-tube, and presumably affect the discharge itself.

The method which I employed did not involve the use of an exploring wire. It is the same which I used to determine the force in the positive column in a discharge through electrolytic gas*.

It depends on the assumption, suggested by experience and, I believe, fully justified by these experiments, that the positive column can be lengthened without making any other sensible change in the steady discharge. Throughout this paper ;

D represents the distance in cms. between the electrodes, always exceeding the distance between the foot of the positive column and the cathode;

$\mathrm{C}$ the steady current passing through the gas and always 0025 ampere;

$X$ the voltage-difference of the electrodes during the discharge;

$Y$ the electric force in volts per $\mathrm{cm}$. in the positive column; and

$p$ the pressure in mms. of mercury.

Then if $\mathrm{D}$ is increased by $d$, the potential-difference of the electrodes required to maintain the same current $\mathrm{C}$ as before under the same conditions will be simply $\mathrm{X}+\mathrm{Y} d$.

In fact if everything is kept constant in the discharge but $\mathrm{X}$ and $\mathrm{D}, \mathrm{X}$ will obviously be a continuous function of $\mathrm{D}$ whatever $D$ 's value. If $D$ is taken as abscissa and $X$ as ordinate a curve can be plotted, and it is easy to verify under favourable conditions that when $D$ exceeds a certain value the curve becomes straight within the limits of experimental error, and that the value in question is about the distance of the foot of the positive column from the cathode. The slope of this straight part of the $D-X$ curve is obviously the electric force $Y$ in the positive column. The advantage of this method is first that the exploring wire is dispensed with, and secondly that the electric force can be determined and verified by several observations with different values of $\mathrm{D}$. The disadvantage is that the observations are not simultaneous, so that if a small change occurs in the region of the discharge near the cathode, where the electric force is very great, relatively large errors may occur in the observations. This difficulty should only be felt when $\mathrm{Y}$ is small; but in oxygen $\mathrm{Y}$ is remarkably small, ranging for pressures

\footnotetext{
* Phil. Mag. March 1907.
} 
less than $5 \mathrm{~mm}$. between 4.5 and 20 volts per $\mathrm{cm}$. in these experiments. Now the cathode fall is about 400 volts, so that if a small change of a few per cent. in the field near the cathode occurs between two observations, it can easily introduce an error of $1 \mathrm{~cm}$. in D. Moreover, it is necessary to keep the current accurately the same, since a very small error in reading it corresponds to a much larger one in $\mathrm{D}$.

The electrical arrangement is represented diagrammatically in fig. 1. $A B P Q$ represents the discharge-tube, supported in such a position that its base dipped under the mercury filling a large jar $\mathrm{J}$. The side tube $\mathrm{T}$ connected the discharge-tube through a drying-tube to a mercury pump, and to an electrolysis apparatus where oxygen was generated and dried. It may be stated here that the oxygen was prepared by the electrolysis of pure barium hydrate, which insures its purity*.

Fig. 1.

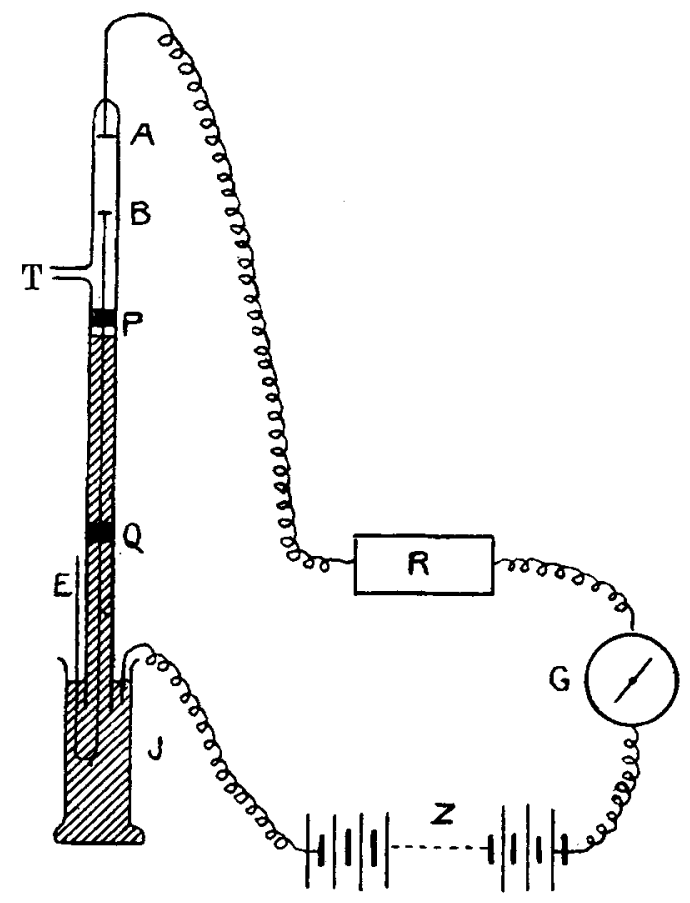

The figure represents the tuhe partly filled by the mercury - the shaded part-when the oxygen was reduced to a low pressure. A is the fixed cathode connected to a platinum

* H. B. Baker, Trans. Chem. Soc. 1902, vol. lxxxi. 
wire fused into the top of the tube. The anode B is attached to an iron rod, which, sliding in the fixed steel guides $\mathrm{P}, \mathrm{Q}$, and bent round the bottom, terminates at $\mathbf{E}$. Thus by raising or lowering $\mathbb{E}$, the movable anode could be adjusted to any distance up to about $30 \mathrm{cms}$. The positive end of the battery $\mathrm{Z}$ was in metallic connexion with the mercury, and so with the anode; and the negative end was connected through a galvanometer $G$ and the variable resistance $R$ to the cathode A. $Z$ was usually of about 1500 volts, $G$ was a high resistance and dead-beat voltmeter, and $\mathrm{R}$ several 100,000 ohms.

With such an apparatus $R$ could be varied and $D$ determined by adjusting the anode till the galvanometer recorded C. And then we may, as stated above, regard $X$ as a linear function of $\mathrm{D}, \mathrm{C}$ and $p$ being constant.

Now $\mathrm{X}$ and $\mathrm{R}$ are connected by the ohmic equation

$$
X=Z-C(R+G),
$$

if $\mathrm{Z}$ denotes the E.M.F. of the battery and $\mathrm{G}$ the resistance of the galvanometer, together with any other invariable resistance in the circuit including that of the battery. Therefore $\mathrm{R}$ is a linear function of $\mathrm{D}$, and the points whose coordinates are $\mathrm{D}, \mathrm{R}$ will determine a straight line, the slope of which multiplied by $\mathrm{C}$ is the electric force in the positive column, since

$$
\mathrm{Y}=\frac{d \mathrm{X}}{d \mathrm{D}}=-\mathrm{C} \frac{d \mathrm{R}}{d \mathrm{D}} \text {. }
$$

The slope of the $D-R$ line was determined throughout the earlier experiments by finding the values of $\mathrm{D}$ corresponding to several different values of $R$. Thus a number of points were plotted, which, if the discharge had been steady, lay upon or close to a straight line. If they did not, 1 often found that some lay very near one line and others fell close to a line parallel and close to the former. That showed in rather an interesting way that the discharge had shifted from one to the other of two slightly different states or positions without, however, affecting the magnitude of the force in the positive column. Sometimes three such parallel lines could be recognized, but of course, if there were more than two such shifts, the corresponding parallel lines cannot easily be detected, and the force $\mathrm{Y}$ can only be estimated, and with considerable error, by drawing the mean locus of the points. Owing to this experience and in order to obviate such shifts, I ultimately determined $Y$, when possible, in a single discharge by diminishing $R$ twice by the same amount 


\section{Positive Column in Oxygen.}

$r-i . e$. by $2 r$ altogether-and determining the corresponding increases $d_{1}, d_{1}+d_{2}$ to $\mathrm{D}$. If $d_{1}$ was nearly equal to $d_{2}$, it was assumed that no alteration had occurred in the discharge outside the positive column to invalidate the experiment; the force $\mathrm{Y}$ was taken to be the mean of $\frac{\mathrm{C} r}{d_{1}}$ and $\frac{\mathrm{C} r}{d_{2}}$, and the difference between $d_{1}$ and $d_{2}$ compared with either as an index of the experimental error. This method is useful when the discharge is unsteady.

When the pressure is less than its value at which $\mathrm{Y}$ is discontinuous, $d_{1}$ is always nearly equal to $d_{2}$, for the points whose coordinates are $\mathrm{D}, \mathrm{R}$ fall accurately upon a straight line. But for pressures above $.8 \mathrm{~mm}$. it is seldom that the discharge remains constant enough to permit the determination of $\mathrm{Y}$ with the same precision. The chief cause of variation is the flickering of the discharge which at the higher pressures does not cover the whole of the cathode nor remain on the same part of it. And if the electrodes become oxidized the trouble increases.

After making experiments with zinc and nearly pure silver electrodes and being much inconvenienced by their oxidation, I tried silver-gilt electrodes. These were much the most satisfactory, and as long as the gold lasted no sign of discolouration appeared on the cathode or discharge-tube. The anode deepened in colour, but only tarnished where the gold was obviously thinnest. The cathode closely fitted the discharge-tube whose diameter was nearly $2 \cdot 4 \mathrm{cms}$. The diameter of the anode was $2 \mathrm{cms}$., so that it could move up and down the tube without touching it.

TABLE I.

\begin{tabular}{|c|c||c|c||c|c|}
\hline$p$. & $\mathrm{Y}$. & $p$. & $\mathrm{Y}$. & $p$. & $\mathrm{Y}$. \\
\hline $2 \cdot 52$ & $5 \cdot 3$ & $5 \cdot 06$ & $19 \cdot 2$ & 3.94 & $12 \cdot 1$ \\
$1 \cdot 85$ & $4 \cdot 5$ & $3 \cdot 28$ & $9 \cdot 3$ & $\cdot 96$ & $10 \cdot 2$ \\
1.48 & $4 \cdot 6$ & $1 \cdot 38$ & $5 \cdot 7$ & $\cdot 802$ & $20 \cdot 0$ \\
.804 & 11.0 & $1 \cdot 16$ & $6 \cdot 25$ & & \\
.802 & $19 \cdot 2$ & $\cdot 56$ & $15 \cdot 4$ & $1 \cdot 21$ & $7 \cdot 8$ \\
79 & $18 \cdot 7$ & & & & \\
\hline
\end{tabular}

The results of experiments with these electrodes are given in Table I., each compartment of which applies to a fresh quantity of oxygen. The errors in the determination of $\bar{Y}$ 
during a given discharge are estimated to be 4 or 5 per cent. except for pressures below $\cdot 8 \mathrm{~mm}$., when the results are much more accurate. The pressures were all measured upon a McLeod gauge.

Table I. is illustrated by the curve in fig. 2 , in which all the points lie satisfactorily near the curve except two, the determinations of which were more uncertain than that of the others.

Fig. 2.

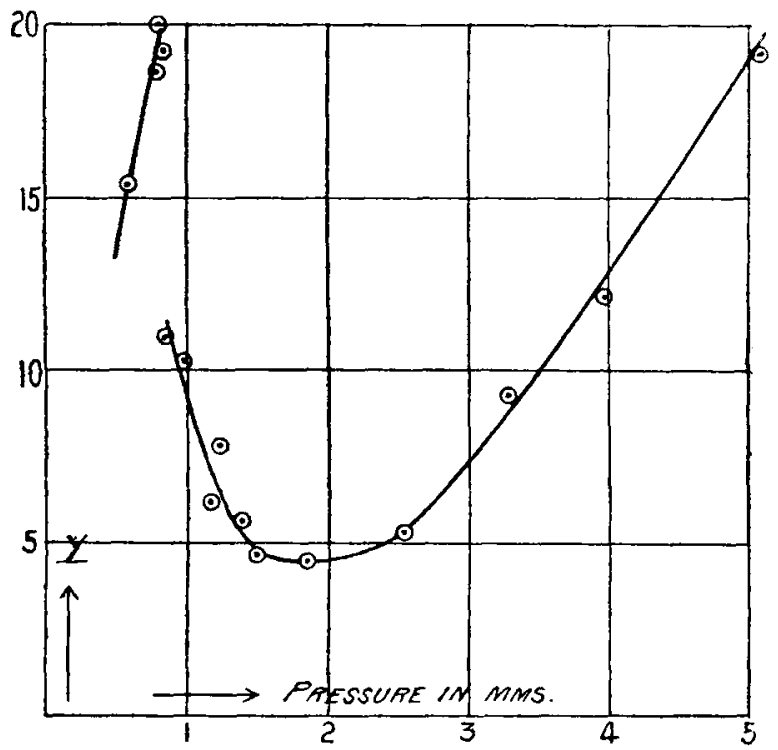

The curve is entirely different from corresponding curves of the other common gases. When $p$ is greater than $1.5 \mathrm{~mm}$. the values of $\mathrm{Y}$ are only between one-tenth and one-fifth of the electric force in a similar positive column in the similarly dense gases nitrogen or carbon monoxide. Again, at the pressure $1.75 \mathrm{~mm}$., Y reaches a minimum with the curiously small value 4.5 volts per $\mathrm{cm}$.

The third peculiar and most interesting feature of the curve is the violent discontinuity which $\mathrm{Y}$ undergoes at the pressure $.8 \mathrm{~mm}$. That the discontinuity is real and not apparent is shown by the fact that $\mathrm{Y}$ then passes suddenly from about 11 to 20 without seeming to assume any intermediate value, and even more by the fact that a complete change seems to come over the discharge, which now settles down into the greatest steadiness. Thus the curve is broken and not merely very steep. The change occurs during a 
discharge, if the pressure of discontinuity is approached very gradually. I have twice noticed immediately after the sudden rise in $\dot{Y}$ the appearance of peculiar striæ so close together that there were 10 within $1.8 \mathrm{~cm}$. That was with the zinc electrodes. It is very seldom indeed that they appear with oxygen.

To investigate the discontinuity in $\mathrm{Y}$ more thoroughly, I connected to the apparatus a large glass tube which could be filled partly or wholly with mercury like the barrel of a mercury pump. With this arrangement the pressure could be varied, and, without introducing new oxygen, could be made to pass backwards and forwards across the point of discontinuity. It was then observed that $\mathrm{Y}$ passed from its low value to its high and back again from high to low, keeping pace with the pressure. This is illustrated by the following simultaneous values of $p$ and $\mathrm{Y}$, which represent a series of experiments upon the same mass of oxygen :-

.95 mm., $10 ; \cdot 84,11 \cdot 4 ; \cdot 765,19 \cdot 2 ; \cdot 802,20 \cdot 0$; $\cdot 88,11 \cdot 6 ; \cdot 81,20$.

It is evident, therefore, that the discontinuity is not brought about because the gas has been vitiated by the discharge. It must be due to some inherent instability in the oxygen when the pressure is slightly greater than $8 \mathrm{~mm}$.

But when a quantity of oxygen had been subjected to a long series of discharges, the pressure can be raised considerably beyond $\cdot 8 \mathrm{~mm}$. where the discontinuity first occurred. Thus on one occasion, after the pressure was reduced below the discontinuity point, it was gradually raised from $.79 \mathrm{~mm}$. to 1.07 without Y's abruptly changing, and $\mathrm{Y}$ reached the abnormally high value 23 . The same phenomenon was observed with the silver electrodes.

The electric discharge therefore tends to prevent the oxygen from recovering the condition roughly defined by $p=-8, \mathrm{Y}=11$. It is natural to attribute this tendency to ozone; especially since the fall of pressure during each of these two series of observations showed the conversion of a considerable amount-probably more than 15 per cent.—of oxygen into ozone.

We may therefore conclude that the presence of ozone checks the repassage of the oxygen through the discontinuity.

When the pressure falls below $\cdot 8$, the slope of the curve $p-\mathrm{Y}$ is very steep; but there is no discontinuity whatever here. On the contrary, $\mathrm{Y}$ is nowhere determined so easily as when $p$ lies between .5 and $\cdot 8 \mathrm{~mm}$. The discharges for this range of pressures are very steady : the readings of $D$ 
are repeated with little error, and the decrease in $\mathrm{R}$, and therefore the increase in $\mathrm{X}$, is strictly proportional to the increase in $\mathrm{D}$-facts which prove that very little change occurs in the region of high force near the cathode during a series of discharges with the same current. This steadiness is shown by Table II., which gives the results of a series of experiments with gradually diminishing pressure upon freshly introduced oxygen during my earlier experiments with zine electrodes (diameter $2 \cdot 1$ cms.). The total duration of the discharges used for these observations was about

TABLe II.

\begin{tabular}{|c|c|c|}
\hline$p$. & $\mathrm{Y}$. & $256 p+9$ \\
\hline 804 & $21 \cdot 4$ & $21 \cdot 5$ \\
\hline 75 & 198 & $20 \cdot 1$ \\
\hline 72 & $19 \cdot 2$ & $19 \cdot 3$ \\
\hline 69 & $18 \cdot 35$ & 18.5 \\
\hline 66 & 17.85 & $17 \cdot 7$ \\
\hline 643 & $17 \cdot 25$ & $17 \cdot 35$ \\
\hline 617 & $16 \cdot 8$ & 16.7 \\
\hline .58 & 158 & $15 \cdot 7$ \\
\hline 534 & $14 \cdot 42$ & $14: 55$ \\
\hline
\end{tabular}

3 minutes; and it may be taken that ultimately 10 per cent. of the gas was ozone. The numbers show an extremely accurate agreement, and prove that the curve is very straight to the left of the discontinuity; for every value of $\mathrm{Y}$ but one differs from $25 \cdot 6 p+\cdot 9$ by less than 1 per cent.

Table II. exhibits great consistency in the observations, which were made rapidly, and all but the first and last with two observations only. In fact it is experiments like these, made with a steady discharge, that establish the validity of the method and prove that the positive column can be lengthened without otherwise sensibly affecting the discharge. We can also infer from the table that the presence of a good deal of ozone does not greatly modify the force $\mathrm{Y}$ when $p$ is less than $\cdot 8$.

Table III. contains the results of experiments, other than those in Table II., made with the zinc electrodes. The percentage errors in the values of $\mathrm{Y}$, most of which were determined by several observations, is not more than 4 and in 
most cases less than 2 or 3 . Each compartment of Table III. applies to experiments upon the same specimen of oxygen.

TABLE III.

\begin{tabular}{|c|c|c|c|c|c|}
\hline$p$ & $\mathrm{Y}$. & $p$ & Y. & $p$ & $\mathbf{Y}$. \\
\hline 1.02 & $7 \cdot 5$ & \multirow{3}{*}{$\begin{array}{l}6 \cdot 26 \\
4 \cdot 2 \\
3 \cdot 2 \\
2 \cdot 42\end{array}$} & \multirow{3}{*}{$\begin{array}{c}15 \\
6 \cdot 6 \\
5 \cdot 25 \\
4 \cdot 04\end{array}$} & 1.02 & 75 \\
\hline$\cdot 495$ & $13 \cdot 1$ & & & 79 & $20 \cdot 4$ \\
\hline 202 & $4 \cdot 6$ & & & .785 & $20 \cdot 4$ \\
\hline & & & & 73 & $19 \cdot 2$ \\
\hline 40 & 8.2 & $2 \cdot 9$ & 59 & 7 & $17 \cdot 6$ \\
\hline $2: 36$ & $4 \cdot 4$ & $\cdot 686$ & $17 \cdot 8$ & $\ldots$ & $\cdots$ \\
\hline 1.49 & $6 \cdot 15$ & $\cdot 49$ & 12.5 & $\cdot 88$ & 117 \\
\hline
\end{tabular}

The numbers in Table III. are with two exceptions sufficiently concordant, although the oxygen had in many cases been subjected to much discharge. They determine a curve which is nearly identical with that of fig. 2 for pressures below $2 \mathrm{mms}$, but falls much below it when $p$ exceeds $2 \mathrm{mms}$. Thus, when $p$ exceeds $4, \mathrm{Y}$ is less than two-thirds of its corresponding value in fig. 2 . This large difference cannot be attributed to the small difference in the discharge-tubes; especially since the latter difference should make-if we can be guided by the behaviour of nitrogen* - the values of $\mathrm{Y}$ in Table III. greater than those in Table I.

Hence the conclusion is forced that the divergence is due to the use of different electrodes. This conclusion is confirmed by my experiments with silver electrodes, which gave a general agreement with the foregoing results for pressures less than $2.5 \mathrm{mms}$, and at first gave the usual pressure of discontinuity. But partly perhaps owing to the cathode's not fitting the tube, and chiefly, I believe, to the oxidation of the electrodes, these experiments left few numbers to rely on or worth recording. It may be remarked, however, that when the electrodes became badly attacked, the pressure of discontinuity was thrown back to the point $\cdot 62 \mathrm{mms}$., and the values of $\mathrm{Y}$ on both sides of it were then reduced to 8 and 18.

* Herz found that the electric force in nitrogen was $99 \cdot 7$ and 89.3 for tubes 10 and $20 \mathrm{mms}$. in diameter respectively.-J. J. Thomson, $l . c$. ch. xv. 
The observation of the discontinuity in $\mathrm{Y}$ at the pressure $.8 \mathrm{~mm}$. immediately recalled the discontinuity of $p v$ observed by C. Bobr * in oxygen at the pressure $7 \mathrm{~mm}$., the history of which is very interesting. Bohr's observations were confirmed by Baly and Ramsay †; but in 1901 Lord Rayleigh $\ddagger$ was unable to detect any signs of such an effect with his extremely accurate manometer, and, at a loss to account for the difference between Bohr's experience and his own, could "only suppose that it must be connected somehow with the quality of the gas complicated perhaps by interaction with the glass or the mercury."

Now, according to Bohr, Boyle's law must be replaced, in the case of oxygen, for temperatures between 11 and 14, by and by

$$
(p+\cdot 109) v=k \text { when } p \text { is greater than } \cdot 7 \mathrm{~mm} \text {., }
$$

$$
(p+\cdot 07) v=k \text { when } p \text { is less than } \cdot 7 \mathrm{~mm} \text {. }
$$

All the pressures given above were measured on a McLeod gauge: and the temperature of the laboratory ranged from $10^{\circ}$ to $15^{\circ}$. Hence, if Bohr's results apply to them, they must be diminished by $\cdot 109$ when $p$ is greater than $\cdot 7 \mathrm{~mm}$., and by $\cdot 07$ when $p$ is less than $7 \mathrm{~mm}$. Moreover, the pressure $\cdot 7$ would be given by the McLeod gauge either as $\cdot 809$ or $\cdot 77$. Thus the pressure of Bohr's discontinuity agrees in the closest way with the pressure at which $\mathrm{Y}$ is discontinuous. Nevertheless, in view of Lord Rayleigh's conclusions, I have not ventured to make any corrections to the estimated values of $\mathrm{my}$ pressures.

The observed discontinuity in $\mathrm{Y}$ points to a molecularly unstable condition reached by oxygen at the pressure in question, such that under the discharge the gas-or possibly only that part of it which is the seat of the dischargepasses from one to the other of two states of molecular equilibrium. In this connexion the suggestion of Sutherland $\S$ in explanation of Bohr's and Sir W. Crookes's anomalies is interesting, that oxygen tends spontaneously to pass into ozone at about $7 \mathrm{~mm}$. pressure. This view receives some support from the conclusion above that the presence of ozone checks the return of the oxygen to the state defined by smaller values of $Y$. I have twice observed at the point of Y's discontinuity curious falls of pressure which would be well explained by Bohr's results, and cannot but conclude that his

* Wied. Ann. vol. xxvii. pp. 459-479 (1886).

$\dagger$ Phil. Mag. vol. xxxviii. p. 301 (1894).

I Phil. Trans. 1901, p. 205.

§ Phil. Mag. vol. xliii. 1897, p. 201. 
discontinuity and the discontinuity in $\mathrm{Y}$ are intimately connected. Is it not a possible explanation of Lord Rayleigh's and Prof. Bohr's different experiences, that the carefully dried tubes of the latter may have developed a high state of electrification by the motion of the mercury, and that thus the gas became subject to electrical disturbances sufficient to effect the transition from one molecular state to the other ?

These experiments were made in the laboratory of Prof. J. S. Townsend, Wykeham Professor of Physics, Oxford.

LIII. Notices respecting New Books.

Condensation of Vapor as induced by Nuclei and Ions. By Carl Barts, Hazard Professor of Physics, Brown University. Washington: Published by the Carnegie Institution. 1907. Pp. ix +164.

IN this monograph the author, whose work on nuclei is well 1. known, describes a number of investigations carried out with his fog-chamber apparatus. The apparatus having been sufficiently improved, it was used for various experiments, including the growth of persistent nuclei, the production of water nuclei by evaporation, the results obtained when $\mathrm{X}$-rays are allowed to strike the fog-chamber from different distances, the effect due to radium, \&c. Other problems dealt with in the book are the distribution of colloidal nuclei and of ions in media other than airwater, the simultaneous variation of the nncleation and the ionization of the atmosphere of Providence, and the variations of the colloidal nucleation of dust-free air in course of time.

Fourier's Series and Integrals. By H. S. CarsLaw. Macmillan and Co. London and New York. 1906.

The complete title is " Fntroduction to the Theory of Fourier's Series and Integrals and the Mathematical Theory of the Conduction of Heat." The book naturally falls into two parts, Part I. being concerned with the purely inathematical developments, and Part II. with the applications to the various practical and ideal problems of heat conduction. Basing on the modern theory of rational and irrational numbers, Professor Carslaw leads up through a logical discussion of the convergence of infinite series to the important forms associated with the name of Fourier, finishing in Chapter VIII. with the Integrals. This part occupies 187 pages in a book of 430 pages. The remainder is devoted to the problems of thermal conduction. Professor Carslaw is to be congratulated on supplying a book which cannot fail to be of great service to several classes of readers. The student of pure mathematics will find his mind directed along the best modern lines of investigation of 